\title{
Diversity characteristics and the experiences of nursing students during clinical placements: A qualitative study of student, faculty and supervisors' views
}

\begin{abstract}
Jane $\mathrm{Koch}^{*}$, Bronwyn Everett*, ${ }^{*+,}$, Jane Phillips" and Patricia M Davidson**
${ }^{\star}$ School of Nursing and Midwifery, University of Western Sydney, Sydney, NSW, Australia; ${ }^{+}$Centre for Applied Nursing Research, South Western Sydney Local Health District, Liverpool, NSW, Australia; !Ingham Institute of Applied Medical Research, Liverpool, NSW, Australia; "Faculty of Health, Centre for Cardiovascular and Chronic Care, University of Technology Sydney, Sydney, NSW, Australia; ${ }^{\star *}$ Faculty of Health, Johns Hopkins University, University of Technology Sydney, Sydney, NSW, Australia
\end{abstract}

\begin{abstract}
AвSTRACT: Background: Little is known about which diversity characteristics if any, impact on nursing students' clinical placements or how these may affect the quality of their learning experiences. There is therefore a need to better understand these effects not only from the student's perspective but also from the perspective of the staff who supervise them, in order to ensure students obtain maximal benefit from their placements. Aim: To describe the clinical experiences of nursing students and the diversity characteristics that affect this learning experience. Methods: Data were collected from a series of open-ended questions embedded within a larger anonymous web-based survey, from August 2011 to March 2012. Participants included first, second and third year undergraduate Bachelor of Nursing students $(N=704)$ and faculty members involved in the clinical learning environment $(N=165)$ from seven Australian universities. Findings: Qualitative findings were clustered into three main themes: differences, difficulty and discrimination, each with three subthemes. Conclusion: Findings suggest a need to offer appropriate support for nursing students who feel different because of diversity characteristics. Whilst some of the participant perceptions are confronting they provide valuable insights for universities developing curricula and the clinical placement facilities where students obtain their experience.
\end{abstract}

KeYwords: qualitative research, nursing students, clinical placement, English as an second language, diversity characteristics, cultural diversity, linguistic diversity

$\mathrm{M}$ igration and social change have radically altered not only society but health care systems (Ollila, 2005; U.S. Department of Health and Human Services, 2011) and the composition of the nursing profession (Ohr, Parker, Jeong, \& Joyce, 2010). Perhaps none is more striking than in nursing; which was once the profession of unmarried young women (American Association of Colleges of Nursing, 2005) and is now diverse and heterogeneous in terms of gender and pathways into the profession (Aktan et al., 2009). In countries such as Australia, there is also political intention to broaden societal participation in universities (Bradley, Noonan, Nugent, \& Scales, 2008). Therefore, in pre-registration nursing programmes there is a range of age, gender, cultural and social groups which creates a diverse learning environment.

Diversity is not only a feature of the nursing profession but the environments in which nurses' work. Countries such as Australia (Australian Bureau of Statistics, 2012), Canada (Gushulak, Pottie, Hatcher Roberts, Torres, \& DesMeules, 2011), the United Kingdom (Office for National Statistics, 2011) and the United States (US Census Bureau, 2012) are host countries to a range of ethnic and cultural groups. Enabling policy environments in these countries also accommodates a range of religious (Ahdar, 2012), cultural (Metcalfe, 2011) and sexual orientations (National Defense Research Institute, 2010). Despite these well-intentioned strategies to support multiculturalism, community harmony and social justice, there are many examples where there are lower levels of tolerance and discrimination and where racism is evident (Berman \& Paradies, 2010). In nursing too, diversity not only establishes a pathway for the development and evolution of nursing, it also creates a potential milieu for disharmony (Habermann \& Stagge, 2010). 
Students who are perceived to be different or perceive they are different can have negative clinical placement experiences (San Miguel, Rogan, Kilstoff, \& Brown, 2006). These students are more likely to encounter prejudice and discrimination from staff and patients during their acute care clinical placements (Amaro, AbriamYago, \& Yoder, 2006; Levett-Jones \& Lathlean, 2009). However, there is little research that has explored their experiences of diversity, either from the undergraduate nursing students' or the supervisors' perspectives and whether diversity characteristics impact on this crucial learning experience. A convergent parallel mixed methods design was chosen for the original study (Koch, 2013). The concurrent collection of quantitative and qualitative data used an anonymous webbased survey asking students about their most recent clinical placement so that their perceptions were current. This mixed method approach was taken to enable a broader and more complete understanding of how diversity influenced the experiences of nursing students undertaking clinical placement and to correlate the two sets of data (students and staff). For the purpose of the study, Loden and Rosener (1991) characteristics of diversity were expanded to include age, gender, ethnicity, language, religious belief, sexual orientation, educational background, income, marital status, parental status, work experience and disability. These elements provided a comprehensive selection of diversity characteristics of interest and relevance to the study. Adopting these diversity characteristics allowed for the overall research question to be answered: That is to determine "What are the relationships between diversity characteristics and the clinical placement experiences of nursing students?' The volume and depth of the qualitative data retrieved demanded that these data be analysed and reported separately so as to give voice to the participants who clearly perceived this to be an important and unexplored area that impacted and shaped their undergraduate nursing learning experiences.

\section{LITERATURE REVIEW}

There is an overall lack of empirical data relating to how the diversity characteristics chosen for the study (age, gender, ethnicity, language, religious belief, sexual orientation, educational background, income, marital status, parental status, work experience and disability) relate to the clinical experiences of nursing students. Much of the literature considered nurse education generally rather than the clinical placements specifically (Koch, Everett, Phillips, \& Davidson, 2014). The few studies that have report on diversity have predominately focussed on gender, age, prior caring experiences and language skills.

Keogh and O'Lynn (2007, p. 257) reported male nursing student being treated 'differently by the nurses,' and not accepted as a nurse during clinical placement. Although men are entering nursing in increasing numbers (Stott, 2007), male students face gender stereotyping and discriminatory behaviour, leading some to reconsider their choice of career. It is important to explore whether these concerns relate to their clinical experiences.

An increase in mature-aged students (over 25 years of age) is reflected in the literature (Gaynor et al., 2007). Often these students, both male and female, have previous work experience, parental responsibilities and often becoming a student has financial implications. Hasson, McKenna, and Keeney (2013) found that were nursing students in paid caring-related employment perceived this as advantageous enhancing confidence, skill development and helped prepare them for the reality of nursing during clinical placements. Some students perceived that previous caring-related employment was detrimental to their learning creating confusion between nursing student and care assistant roles. Those with no prior caringexperience felt disadvantaged, and felt their lack of caring-experience negatively influenced their clinical learning and their ability to fit into the nursing team (Hasson et al., 2013). Financial problems during clinical placements were identified by Gidman, McIntosh, Melling, and Smith (2011) particularly for single parents, with some students considering leaving their programmes due to their financial difficulties. There is no literature relating to overseas qualified nurses who chose to become nursing students in Australia.

No literature explored how ethnicity impacted on clinical experiences although there is more 
literature relating to the English language skills of ethnically diverse students. Students identified clinical placements as particularly challenging when language skills were limited (Donnelly, McKiel, \& Hwang, 2009). They experienced difficulties in understanding conversations between patients and clinicians, how the use of technical terms and Australian idioms was like a 'third language' (Crawford \& Candlin, 2013). Similar findings were reported in an earlier study and also included difficulty understanding handover reports as the nurses spoke quickly and used terminology and abbreviations with which students were unfamiliar (San Miguel et al., 2006).

There is a lack of empirical data related to students with special needs particularly in terms of the challenges faced by students with a disability during their clinical placements. Much of the literature focuses on dyslexia, revealing that students felt isolated and different, performed worse under pressure and did not like asking for help (Sanderson-Mann, Wharrad, \& McCandless, 2012) and feared being ridiculed and discriminated against in the clinical area (Ridley, 2011).

As clinical placements are crucial for students, not only in obtaining and refining clinical skills (Siggins Miller Consultants, 2012) but also for helping socialise students into the profession of nursing (Levett-Jones \& Lathlean, 2009), it is imperative that the increased diversity within the clinical environment does not affect their learning experiences. Given the significant benefits associated with preparing a diverse nursing workforce, it is essential that we better understand the impact of diversity on nursing students clinical placement experiences from both the perspective of the student and those who supervise them. This understanding could help ensure students obtain maximal benefit from their placements.

\section{Aim OF THE STUDY}

This paper reports the qualitative findings from a larger mixed methods study and describes the clinical experiences of nursing students and the some of the diversity characteristics that relate to this experience.

\section{Methods}

\section{Instrument development}

Item generation for both student and staff surveys consisted of structured, closed-ended questions that included socio-demographic characteristics.

For the student survey, four self-report measures were investigator developed: Confidence in clinical communication, diversity orientation, cultural competence and positive experience during clinical placement. A final item related to how their last clinical placement could have been improved. For example, for students, a seven-item self-efficacy scale with items for listening, speaking, reading and writing was developed to report confidence in clinical communication. A validated tool, the English Language Acculturation Scale (ELAS) was used to measure the linguistic aspects of acculturation (Salamonson, Everett, Koch, Andrew, \& Davidson, 2008). Open-ended questions asking for student responses followed each measure. The survey was piloted by current nursing students $(N=34)$ and staff $(N=30)$ involved in planning, teaching or supervising the clinical placements of nursing at one of the study sites.

\section{Participants}

An invitation was sent via the Council of Deans of Nursing and Midwifery to all universities who provide a 3-year tertiary programme as preparation for nursing registration in Australia $(N=38)$. Seven universities agreed to participate.

Nursing students, clinical supervisors (predominantly facilitators employed by the university) and faculty members with direct experience in Bachelor of Nursing (BN) courses at the seven universities were invited to participate by email. The non-randomised convenience sampling strategy recruited 704 nursing students and 165 staff who completed the survey. The percentage of student participants at the seven universities ranged from 2.6 to $26.3 \%$ of the total sample. Most of the respondents were enrolled in an undergraduate $\mathrm{BN}$ course $(N=628)$ and indicated that nursing was their first choice at university $(N=621)$. International students comprised $14.5 \%(N=100)$ of the sample. The majority of nursing students were in the second year of their course $(N=276)$. 
The length of the last clinical placement varied with just over two-thirds of students attending a placement between 1 and 3 weeks $(N=486)$.

Most of the participants were female $(N=620)$, and born in Australia $(N=465)$. Participants who were the first in their family to attend university comprised $40.6 \%(N=279)$ of the student sample. Just over a quarter of the respondents spoke a language other than English at home $(N=197)$. During the semester, $71.6 \%$ of students $(N=$ 492) were engaged in paid work, and $61.5 \%$ of those $(N=302)$ were in nursing or care-related employment. Ages ranged from 17 to 61 years, with a mean age of 28 years ( $S D \pm 9.86)$.

Most of the staff participants were female (88.6\%), and $9.8 \%$ of the participants spoke a language other than English at home. The percentage of staff at the seven universities ranged from 6 to $38.3 \%$ of the total sample. The majority of staff were facilitators, supervising and teaching students during their clinical placements (61.1\%).

\section{Data collection}

The data was collected from August 2011 to March 2012 using web-based surveys, one for students and the other for staff. The survey comprised demographic and quantitative items with the opportunity for open-ended responses regarding participants' views on aspects of diversity and clinical placement. The rationale for using both student and staff data in the parent study is that little is known about which diversity characteristics if any, may lead to nursing students feeling different to their peers during their clinical placements and how this may affect the quality of their clinical experiences. Therefore there is a need to better understand these effects from the student's perspective and also from the perspective of the staff who supervise them. In this paper, both have been included to add perspective.

\section{Ethical considerations}

Ethics approval for the study was granted by all participating universities. Informed consent, assurances of anonymity, freedom to participate/withdraw from the study at any time and information about the study were included in a participant information sheet for both students and staff. Contact details of researchers and the Human Research Ethics Committee were provided. No incentive was offered to participate in the study.

\section{Data analysis}

The open-ended comments were exported from the web-based survey site into text files. They were analysed thematically as one text (Thomas, 2006) by two researchers who were RNs, nurse educators and involved in research, one generally more directed towards educational research and the other patient care (Jane Koch, Patricia M Davidson). They were not involved directly with the participants; this was done by a contact person at each site. The process began in the early stages of data collection when downloaded files were read during the data collection phase for familiarity with the content. When both the student and staff surveys were closed, the full analysis commenced. This inductive process involved multiple readings of the open-ended responses, labelling relevant text sections that mentioned experiences during clinical placement. These labels were refined into themes that reflected diversity (Thomas, 2006).

\section{Rigour}

The analysis of qualitative data is inevitably influenced by the researchers' backgrounds and life experiences (Denzin \& Lincoln, 2008; Thorne, 2000) and thus the interpretation here may differ to how others might approach the data. However, the analysis included consultation in the research team to refine the themes and the findings are presented here with quotes to support the interpretation. Some of the quotes from the data have been edited in very minor ways to help readability.

The COREQ: Consolidated criteria for reporting qualitative research informed the reporting of these data (Tong, Sainsbury, \& Craig, 2007). Due attention was paid to ensuring to: Clarification and justification; procedural rigour; representativeness; interpretive rigour; reflexivity and evaluation rigour; and transferability (Kitto, Chesters, \& Grbich, 2008). 


\section{FINDINGS}

The qualitative data provided a range of information giving context to the clinical environment beyond the intention of the original research. Both student and staff participants acknowledged that the clinical environment was challenging and explained that students are commonly propelled into a foreign environment that was alienating and did not always meet their learning expectations. The misalignment of theoretical issues taught in class and practical experiences was frequently cited, and as such will be reported separately. However, this and other findings provide an important context and backdrop for considering diversity in contemporary clinical environments. Specific diverse characteristics were perceived by both student and staff participants to make a difference to student experiences. A spectrum of experiences were acknowledged, some positive and others negative with some participants' acknowledging and accepting the differences. Some participants recognised that 'being different' did present difficulties, with some indicating that these, separately or together, sometimes appeared to be the basis for inappropriate situations. These varied from unacceptable comments to overt racism and ageism.

The focus of this paper pertains to diversity and the three major themes within this construct were 'difference,' 'difficulty' and 'discrimination' and their sub-themes. Diversity is interpreted to include not only the modified Loden and Rosener's (1991) characteristics, but also the diverse quality of the facilities where students undertook their placement - some good but often not so good, which led to 'an extra pair of hands' being used in both positively and negatively in terms of student learning. This also applied to the quality of the $\mathrm{RN}$ supervision, where some 'just walked away.'

\section{Difference}

The three sub-themes within this theme were 'being and feeling,' 'experience, exposure and expectation' and 'an extra pair of hands,' which reflected the spectrum of differences for placement quality.

\section{Being and feeling}

Although ethnicity and culture were noted by some students, the main difference noted by and about students with English as a second language (ESL) was because of their limited language skills:

I have different accent from local people, and my speaking was hard to understand for nurses $[\ldots]$. 382_30_3 3 rd $\_$year

However, many students of Anglo-ethnicity felt different and excluded because they were the only native English-speaking student:

I was the only Domestic student at my placement and they all spoke their first languages to one another and didn't speak English when around the other students so I felt like a outsider. 624_28_2 $2^{\text {nd }} \_$year

In some situations, student participants also noted that speaking English fluently had distinct advantages:

English was my first language, I was more proactive about my learning experience, I was more confident, I seemed to know more than they did. $69 \_28 \_2^{\text {nd }}-$ year

Age and maturity were major areas of difference reported. Younger nursing students had negative comments about feeling different, but for older participants this was a double-edged sword. In some situations they perceived that their life experiences were an advantage, being more confident and able to 'speak up,' yet in other settings a disadvantage leading to a sense of uncertainty because of facility staff expectations of increased knowledge and experience:

I felt that my young age had a great impact on my clinical experience and my lack of acquired life skills and nursing knowledge affected my confidence and the perception of others towards me. 374_25_2 $2^{\text {nd }} \_$year

I feel that being older has benefits as maturity and life experience is advantageous in many aspects of nursing. 322_29_3 ${ }^{\text {rd }} \_$year

\section{Experiences, exposure and expectation}

Although students commented that clinical staff were often not aware of their objectives or previous experiences, it was apparent that some staff recognised the wide spectrum 
of experiences and the value of exploring these with students. Student participants with previous care associated experiences found that their familiarity and confidence in the clinical environment enabled them to show initiative. This helped them integrate into the work team more easily. Some students with an enrolled nurse qualification often felt different because of their different student role and the expectations that they were clinically competent. Both students and staff commented that students needed more and longer exposure to the 'real world' of nursing,' learning more in the clinical areas than in the classroom:

I recognise they [nursing students] have different experiences and different exposure so I have to explore that. 75_1_Staff_facilitator_lecturer

I was older than the other students and was the only one with previous experience. Therefore the existing staff when they were under pressure sometimes chose me more to help them than the other students. 309_30_1 ${ }^{\text {st }}$ year

[...] What was new and confronting to other students was not to me. 474_29_year_not disclosed

Irrespective of the year of their degree, older students felt that there were higher expectations placed on them by staff. If the older students also had previous nursing experiences they perceived that they were used as a resource, providing direction, help and support to their less experienced peers. They also perceived that they were often given enhanced responsibilities by the placement staff, in some instances beyond their level of competence as a nursing student:

The nursing staff and doctors know me and were at times treating me as a fully qualified nurse as they know my experience. 404_30_2 $2^{\text {nd }} \_$year

Parental responsibilities were cited by numerous student participants as making them feel different to their peers with an expectation that there should be awareness of their needs, such as the necessity to leave the facility on time to pick up children from care:

I am a single mother, and have responsibilities that aren't catered for by ${ }^{* * * * *}$, nor understood by my facilitator. 65_28_2 $2^{\text {nd }} \_$year
This conflicted with staff participants who perceived that single parents and students with children expected their requests to be prioritised over others.

Although not elaborated, male students reported that their gender had advantages during their clinical placements:

I was treated differently in a positive way only because I believe I was male ... 540_30_2 $2^{\text {nd }} \_$year

High achieving students felt that they were excluded from social activities as their peers perceived them as different. Some participants commented that their personal qualities, such as values, interests, work ethic and attitudes to learning had a positive experience on their clinical learning experiences:

I felt different from some of the students because I was keen to learn and put the effort in. You take every minute of your time to learn something new. $193 \_28 \_2^{\text {nd }} \_$year

Some students emphasised the equality in diversity:

By all being different, I didn't feel different. Just one in the mix. 620_28_3 $3^{\text {rd }} \_$year

\section{An extra pair of hands}

Some students responded about their supernumerary status during clinical placements and how these 'extra pairs of hands' were used both positively and negatively. This often reflected the differences in quality of the clinical placements. Comments provided by both students and staff indicated vast differences in the quality of clinical experiences. Both challenged the relevance and appropriateness of some clinical placements because of misalignment between theoretical objectives and practical experiences and in terms of being inappropriate for level of students.

Students questioned being used as an additional 'pairs of hands,' the appropriateness of their supervision by facility staff and their learning experiences. They emphasised the need for more opportunities to practice, not only during the placement but also at university:

I think we were treated equally badly and treated as an extra pair of hands to do showers and obs. 135_30_2 $2^{\text {nd }} \_$year 


\section{Difficulty}

Student and staff participants told of the challenges and consequences of diversity, which caused difficulties, particularly in the areas of language literacy, income and parental responsibilities. Students also found that they were often unprepared for aspects of cultural and linguistic diversity encountered during their clinical placement.

\section{Not prepared for diversity}

Students and staff perceived that universities dealt adequately with Indigenous health but other aspects of cultural and linguistic diversity were not generally well covered in undergraduate nursing programmes and emphasised the importance of integrating diversity concepts in the curriculum:

[...] As a BN grad entry student, with the exception of Indigenous studies cultural practice has not been covered [...]. 436_33_2 $2^{\text {nd }}-$ year

Many student participants also showed insight into the limitations of the care provided to patients who were culturally and linguistically diverse:

[...] More focus on communicating with patients who speak languages other than English. 652_33_3 ${ }^{\text {rd }}$-year

Staff participants had conflicting perceptions of students' awareness of diversity, that diversity was not a 'big deal' for students, being accepted as a normal part of life and learning. Other comments from staff indicated that students are not sensitive to diversity or had minimal exposure to diversity:

I believe that although the concept of diversity amongst students is recognized by all there is little or no instruction given to understand the diversity and ways to equitably manage it. 70_5_facilitator_lecturer

Despite the perception that there was a need for more preparation regarding the breadth of diversity, some student participants were very idealistic about caring for diverse clients:

To me my patient is a human being and their culture, ethnicity, race, sexuality or gender status does not matter ... They will always receive my best care. 289_29_1 $1^{\text {st }}$ year

\section{Speaking up}

Student and staff both perceived that students who were different, particularly those from diverse ethno-cultural backgrounds, were treated unfavourably during clinical placements by facilitators and RN supervisors. Others commented that incorrect assumptions were often made about students who spoke ESL. This impacted on confidence and learning experiences:

I am saddened by different treatment of international students or for those that English is a 2nd language, by some facilitators or staff. My perception is that people can't be bothered with those that don't speak English well and are short with them or don't take time to communicate with this group of students. $444 \_34 \_2^{\text {nd }} \_$year

I find that students of ethnic persuasions are seen by nursing staff as 'harder' to teach and it is assumed that they know less. 70_4_facilitator_lecturer_RN (clinical)

English language literacy was elaborated by staff as causing numerous difficulties: Students were not gaining the full benefit from clinical placement, not offered the same opportunities to learn, were avoided by clinical nursing staff, required additional time for facilitation, compromised safe practice and were a source of frustration because of their poor language skills. Staff also commented that students with ESL may not always take up opportunities for literacy support and found ways to 'fly underneath the radar' (100_5_Staff) during clinical placements:

Numerous students from CALD backgrounds are struggling to meet the requirements of adequately comprehending instructions/information, expressing themselves adequately \& meeting safe standards of accurate medico-legal documentation. This is also evident in the classroom. While my ethos is strongly based on cultural inclusion the clinical reality is that the language/communication \& literacy levels are frequently not adequate to ensure safe nursing practice. 100_3_facilitator_lecturer_RN (clinical)

As well as affecting the learning experiences of the nursing students with ESL, it also affected students who spoke English as a first language feeling some responsibility to act as an interpreter for them. In some placements, both staff and 
students had limited English skills and this compromised their learning opportunities:

International students with limited English skills have a hard time on placement, but it is also difficult for their English speaking peers because it falls to them to help and guide them. I find it hard work being followed around by my fellow students, I am trying to learn and they are depending on me to help them communicate. 25_5_3 3 rd year

Student participants were challenged at times when conversing with staff with ESL and this negatively affected their learning experiences:

I was placed with a nurse who did not speak very good English and it was hard to communicate my objectives and what was in my scope of practice. 514_30_2 $2^{\text {nd }}$ year

\section{Surviving financially}

A recurring theme from both student and staff was the financial strain that clinical placements place on some students. This was predominantly due to the students being unable to undertake part-time employment but extended to accommodation for rural placements and travel expenses:

The hardest thing about clinical placements is surviving financially during this time. With no extra support from Centrelink during this time and with assignments due I found I was struggling a lot. I had to work a Saturday shift to be able to afford groceries and working 6 days a week and doing my assignments on my only day off was just exhausting. 277_34_1 $1^{\text {st }}$-year

It must be hard for students to work for three to four weeks with no pay whatsoever, and also whilst doing clinical are unable to work at their usual source of income in part-time work. 18_8_Facilitator

\section{Discrimination}

Both staff and student cited instances of inappropriate comments, attitudes, behaviour, intolerance, discrimination, prejudice and racism. These indicated that nursing was not always a caring community within the 'work experience' of the clinical environment.

\section{Prejudices do prevail}

Comments included examples of inappropriate name-calling, lack of respect, a poor understanding of language and cultural barriers and instances of prejudice, discrimination and stereotyping:

Many of the older students feel prejudiced by hospital staff both in attitude toward their age and the opportunities for positions. Some wards are out rightly prejudiced toward some international students, particularly the Chinese rather than other nationalities. 8_56_lecturer_facilitator

Racial prejudices do prevail in our country and English as second language students from racial minorities do suffer from these prejudices. 68_3_facilitator

Both staff and students noted an adverse workplace culture, in terms of conflict between facility staff and attitudes towards students by staff and sometimes facilitators:

The health professionals are not welcoming, or understanding. I felt that the culture of the ward was so stressful [...]. The RN's would also insult us on our lack of skills; this made me feel angry as I have limited experience. I felt unsupported, for example, I was often practicing unsupervised. 505_34_1 $1^{\text {st }}$-year

Students who are 'different' are perceived as a burden and unwelcomed by teams which are struggling to maintain their own integrity, often staff will variously scapegoat, bully, persecute, ignore, criticise students in general, but in particular they will tend to seize on difference. 105_4_facilitator

\section{Send them home}

Racism was perceived and observed by both student and staff. Comments were explicit, indicating inappropriate discourse occurring between students, between facility staff and students and also between patients and students, for example a patient refusing care from a student who was Asian (213_25_2 nd $\_$year).

The majority of comments related to ethnicity, race and language, including instances where racism was reported but ignored:

I've worked a lot with students with variable English skills and it's a HUGE problem. I believe it's a lightning rod for racism. 35_8_Staff_facilitator_lecturer_ RN (clinical)

Sometimes where there are high levels of dissatisfaction within nursing teams you will even find racism 
and other forms of prejudice and externalisation of their own dissatisfaction. 105_4_Staff (facilitator)

In today's society, some academic staff are concerningly racist! 8_32_Staff_lecturer

Some comments indicated that there is need for acceptance of differences within the both groups:

My last clinical placement was fine. Just improve the international students please or send them home. 77_32_1 ${ }^{\text {st }}$-year

[...] My Placement Facilitator did voice discomfort with 'the number of new, non-Australian nurses who happened to be flooding the Australia nursing scene.' This statement and further comments were made based on the new, non-Australian nurses' ethnicity/ accent/original nationality/cultural practices - with blatant disregard for the nurses' personal strengths, love for Australia, intelligence, commitment to nursing, and/or other assets. 303_30_3 $3^{\text {rd }} \_$year

\section{Just walked away}

Some participants reported encountering inspiring, supportive and enabling staff, but the majority did not. Students reported some facility staff as unsupportive, unwelcoming, unapproachable, unhelpful and just 'just walked away' (432_34_3 ${ }^{\text {rd }} \_$year). Staff participants questioned facility staff commitment to students and reported negative attitudes:

Some of my placements have made me regret pursuing nursing as a career. If I had known what I know now I would have considered a different profession. 663_34_3 $3^{\text {rd }} \_$year

\section{Discussion}

These findings have provided an important insight into the perspective of both students and staff in the complex, diverse clinical practice environment. The anonymity of the web-based survey generated candid disclosures that indicate how diversity characteristics in nursing students relate to their clinical experiences.

In the current study, the diversity characteristics defined by Loden and Rosener (1991) have affected the experiences of nursing students during their clinical placements.
Although in some situations these have had positive consequences (e.g., previous care associated work experience), language, ethnicity, age, income, parental status have important negative effects. Many factors have been shown to impact on students experiences during their clinical placements including belongingness (Levett-Jones \& Lathlean, 2008), confidence and anxiety (Chesser-Smyth, 2005) and that students' self-confidence can be easily undermined by inappropriate attitudes of their preceptors (Chesser-Smyth \& Long, 2013).

Our findings indicated that males were welcomed and treated positively during their placements, which may indicate more of an acceptance of male students than shown in previous studies (O’Lynn, 2004; Stott, 2007). Poor language skills have been shown to have negative experiences during clinical placements (Mattila, Pitkäjärvi, \& Eriksson, 2010) and that support prior to clinical placement can improve communication skills and confidence and lead to a positive clinical experience (San Miguel et al., 2006). It would appear that language literacy remains a real problem, with suggestions that linguistic support may not be taken up by some students. This is the first study that has shown that students who speak English as a first language perceive their learning may be adversely affected by being with staff and students who speak ESL.

Although Amaro et al. (2006) reported that recently-graduated, ethnically diverse registered nurses encountered prejudice and discrimination from both staff and patients, there are fewer references in the literature as to whether it could be interpreted as racism. It has been reported that 1 in 10 Australians holds racist beliefs (Dunn, Forrest, Burnley, \& McDonald, 2004) and that the challenges that this implies have to be addressed (Berman \& Paradies, 2010). Johnstone and Kanitsaki (2009, p. 63) describes 'the illusion of non-racism in health care' based on the belief that 'racism is not an issue any more.' At the level of student diversity and clinical placements it would be comforting to agree but this data would suggest differently. 
Older student participants and those with previous care associated experience felt that this often had positive consequences on their learning experiences. However, it is disconcerting that older students were often given more responsibility based on assumptions made by staff that they have experience, giving advice to their peers and also being treated as a qualified nurse. That younger students, with little nursing experience, feel especially vulnerable, indicates how this demographic has changed (Salamonson, Everett, Koch, Andrew, \& Davidson, 2012) from being the mainstay of the nursing student population and the consequence of this change requires more investigation.

It is apparent that in order for the clinical learning environment to be more supportive for students we need to fully appreciate the consequences of diversity within groups (Qin, O’Meara, \& McEachern, 2009).

The spectrum of differences in clinical placements quality had major implications particularly with students perceived as different or who actually feel different. They may be more vulnerable to this variation. It is essential that this is addressed by creating effective academicservice partnerships to relook at the appropriateness of clinical education (Nabavi, Vanaki, \& Mohammadi, 2012). Of importance here are the negative attitudes of some registered nurses to working with students during their clinical placement as teaching is one of the competency standards for the registered nurse (Australian Nursing and Midwifery Council, 2006).

If we are to achieve cross-sector social participation (Bradley et al., 2008) we need to be receptive to individuals who have particular needs, such as parental and financial. Nursing students do undertake paid work and the negative effect of increased hours worked and academic performance is known (Salamonson et al., 2012) but the consequences of being unable to work during clinical placements is less known. These consequences need to be further researched but would seem to add support for new models of undergraduate nursing education to include faculty approved nursing-related paid employment (Salamonson et al., 2012). With the need to rethink and reform professional education to adapt core competencies appropriate for all countries and health professions (Frenk et al., 2010) and the move towards interprofessional clinical placements (Henderson \& Alexander, 2011), an awareness of the effects of diversity is vital.

\section{Limitations}

The questionnaire focussed on diversity and may have elicited strong views. Responder bias could be apparent based upon previously negative experiences. The sampling frame and design preclude generalising these studies more broadly. However there are several strengths. The anonymity of the web-based questionnaire allowed frank disclosure around a contested and complex topic than would have been difficult to elicit by alternate methods such as interviews and focus groups. The multicentre study design allowed a range of participants.

\section{ConClusion}

This study has shown in a sample of both students and staff that diversity characteristics do impact negatively on the clinical experiences of nursing students, specifically age, English language literacy, finance and parental status. A new finding was the negative effects on students with English as a first language who felt that their learning experiences were compromised in some clinical environments. Low English language literacy amongst both nursing students and staff within the clinical environment appears to have added an additional layer of complexity to a health care system that is under increasing pressure. Student diversity characteristics, particularly age and ethnicity, may increase the intolerance, prejudice and racism shown towards them within the clinical learning environment. Increased dialogue between universities and clinical facilities is required to address issues arising from diversity within the clinical setting, to include making clinical practice experiences more responsive to student's lives.

Given the increasing forces of globalisation, migration and widening participation, these issues are likely to increase. Ignoring them has the capacity to impact adversely on student's learning experiences and likely influence their practice as a professional nurse. 


\section{REFERENCES}

Ahdar, R. T. (2012). How well is religious freedom protected under a bill of rights? Reflections from New Zealand. University of Queensland Law Journal, 29(2), 279-296.

Aktan, N. M., Bareford, C. G., Bliss, J. B., Connolly, K., DeYoung, S., Lancellotti Sullivan, K., et al. (2009). Comparison of outcomes in a traditional versus accelerated nursing curriculum. International Journal of Nursing Education Scholarship, 6(1), 1-11.

Amaro, D. J., Abriam-Yago, K., \& Yoder, M. (2006). Perceived barriers for ethnically diverse students in nursing programs. Journal of Nursing Education, 45(7), 247-254.

American Association of Colleges of Nursing. (2005). White paper: Faculty shortages in baccalaureate and graduate nursing programs: Scope of the problem and strategies for expanding the supply. Washington, DC: Author.

Australian Bureau of Statistics. (2012). Cultural diversity in Australia. Reflecting a nation: Stories from the 2011 census. Retrieved from http://www.abs.gov. au/ausstats/abs@.nsf/Lookup/2071.0main+featu res902012-2013\#

Australian Nursing and Midwifery Council. (2006). National competency standards for the registered nurse. Retrieved from http://anmc. org.au/userfiles/file/competency_standards/ Competency_standards_RN.pdf

Berman, G., \& Paradies, Y. (2010). Racism, disadvantage and multiculturalism: Towards effective anti-racist praxis. Ethnic and Racial Studies, 33(2), 214-232.

Bradley, D., Noonan, P., Nugent, H., \& Scales, B. (2008). Review of Australian higher education: Final report (No. 978-0-642-77805-5). Canberra, ACT: Commonwealth of Australia.

Chesser-Smyth, P. A. (2005). The lived experiences of general student nurses on their first clinical placement: A phenomenological study. Nurse Education in Practice, 5(6), 320-327.

Chesser-Smyth, P. A., \& Long, T. (2013). Understanding the influences on self-confidence among first-year undergraduate nursing students in Ireland. Journal of Advanced Nursing, 69(1), 145-147.

Crawford, T., \& Candlin, S. (2013). A literature review of the language needs of nursing students who have English as a second/other language and the effectiveness of English language support programmes. Nurse Education in Practice, 13(3), 181-185.
Denzin, N. K., \& Lincoln, Y. S. (2008). Collecting and interpreting qualitative materials. Thousand Oaks, CA: Sage.

Donnelly, T. T., McKiel, E., \& Hwang, J. (2009). Factors influencing the performance of English as an additional language nursing students: Instructors' perspectives. Nursing Inquiry, 16(3), 201-211.

Dunn, K. M., Forrest, J., Burnley, I., \& McDonald, A. (2004). Constructing racism in Australia. Australian Journal of Social Issues, 39(4), 409-430.

Frenk, J., Chen, L., Bhutta, Z. A., Cohen, J., Crisp, N., Evans, T., et al. (2010). Health professionals for a new century: Transforming education to strengthen health systems in an interdependent world. The Lancet, 376(9756), 1923-1958.

Gaynor, L., Gallasch, T., Yorkston, E., Stewart, S., Bogossian, F., Fairweather, C., et al. (2007). The future nursing workforce in Australia: Baseline data for a prospective study of the profile, attrition rates and graduate outcomes in a contemporary cohort of undergraduates. Australian Journal of Advanced Nursing, 2(25), 11-20.

Gidman, J., McIntosh, A., Melling, K., \& Smith, D. (2011). Student perceptions of support in practice. Nurse Education in Practice, 11(6), 351-355.

Gushulak, B. D., Pottie, K., Hatcher Roberts, J., Torres, S., \& DesMeules, M. (2011). Migration and health in Canada: Health in the global village. Canadian Medical Association Journal, 183(12), E952-E958.

Habermann, M., \& Stagge, M. (2010). Nurse migration: A challenge for the profession and health-care systems. Journal of Public Health, 18(1), 43-51.

Hasson, F., McKenna, H. P., \& Keeney, S. (2013). A qualitative study exploring the impact of student nurses working part time as a health care assistant. Nurse Education Today, 33(8), 873-879.

Henderson, A., \& Alexander, H. (2011). Developing a model for interprofessional education during clinical placements for medical and nursing undergraduate students. Mt Gravatt, QLD: Griffith University and Australian Learning and Teaching Council.

Johnstone, M.-J., \& Kanitsaki, O. (2009). The spectrum of 'new racism' and discrimination in hospital contexts: A reappraisal. Collegian: Journal of the Royal College of Nursing Australia, 16(2), 63-69.

Keogh, B., \& O’Lynn, C. (2007). Male nurses' experiences of gender barriers: Irish and American perspectives. Nurse Educator, 32(6), 256-259.

Kitto, S. C., Chesters, J., \& Grbich, C. (2008). Quality in qualitative research. Medical Journal of Australia, 188(4), 243. 
Koch, J. (2013). Experiences of nursing students undertaking clinical placement in a bachelor degree: A perspective of diversity (Doctoral thesis). Sydney, NSW: University of Technology.

Koch, J., Everett, B., Phillips, J., \& Davidson, P. M. (In Press). Is there a relationship between the diversity characteristics of nursing students and their clinical placement experiences? A literature review. Collegian. doi:10.1016/j.colegn.2014.03.007

Levett-Jones, T., \& Lathlean, J. (2008). Belongingness: A prerequisite for nursing students' clinical learning. Nurse Education in Practice, 8(2), 103-111.

Levett-Jones, T., \& Lathlean, J. (2009). The ascent to competence conceptual framework: An outcome of a study of belongingness. Journal of Clinical Nursing, 18(20), 2870-2879.

Loden, M., \& Rosener, J. B. (1991). Workforce America! Managing employee diversity as a vital resource.

New York, NY: Irwin.

Mattila, L.-R., Pitkäjärvi, M., \& Eriksson, E. (2010). International student nurses' experiences of clinical practice in the Finnish health care system. Nurse Education in Practice, 10(3), 153-157.

Metcalfe, A. (2011). Workplace diversity strategy 2011-13. Canberra, ACT: Department of Immigration and Citizenship.

Nabavi, F. H., Vanaki, Z., \& Mohammadi, E. (2012). Systematic review: Process of forming academic service partnerships to reform clinical education. Western Journal of Nursing Research, 34 (1), 118-141.

National Defense Research Institute. (2010). Sexual orientation and U.S. military personnel policy (No. 2010941362). Santa Monica, CA: RAND Corporation.

Office for National Statistics. (2011). Migration statistics quarterly report. Retrieved from http://www.ons.gov. $\mathrm{uk} / \mathrm{ons} /$ taxonomy $/$ search $/$ index.html?pageSize $=50 \&$ so rtBy=none\&sortDirection=none\&newquery=born+o verseas\&nscl=International+Migration

Ohr, S. O., Parker, V., Jeong, S., \& Joyce, T. (2010). Migration of nurses in Australia: Where and why? Australian Journal of Primary Health, 16(1), 17-24.

Ollila, E. (2005). Global health priorities: Priorities of the wealthy? Globalization \& Health, 1, 1-5.

O'Lynn, C. E. (2004). Gender-based barriers for male students in nursing education programs: Prevalence and perceived importance. Journal of Nursing Education, 43(5), 229-236.

Qin, J. G., O’Meara, B., \& McEachern, S. (2009). The need for an integrated theoretical framework for researching the influence of group diversity on performance. Management Research News, 32(8), 739-750.
Ridley, C. (2011). The experiences of nursing students with dyslexia. Nursing Standard, 25(24), $35-42$.

Salamonson, Y., Everett, B., Koch, J., Andrew, S., \& Davidson, P. M. (2008). English-language acculturation predicts academic performance in nursing students who speak English as a second language. Research in Nursing \& Health, 1(31), 86-94.

Salamonson, Y., Everett, B., Koch, J., Andrew, S., \& Davidson, P. M. (2012). The impact of term-time paid work on academic performance in nursing students: A longitudinal study. International Journal of Nursing Studies, 49(5), 579-585.

San Miguel, C., Rogan, F., Kilstoff, K., \& Brown, D. (2006). Clinically speaking: A communication skills program for students from non-English speaking backgrounds. Nurse Education in Practice, 6(5), 268-274.

Sanderson-Mann, J. J., Wharrad, H., \& McCandless, F. (2012). An empirical exploration of the impact of dyslexia on placement-based learning, and a comparison with non-dyslexic students. Diversity \& Equality in Health \& Care, 9(2), 89-99.

Siggins Miller Consultants. (2012). Promoting quality in clinical placements: Literature review and national stakeholder consultation. Adelaide, SA: Health Workforce Australia.

Stott, A. (2007). Exploring factors affecting attrition of male students from an undergraduate nursing course: A qualitative study. Nurse Education Today, 27(4), 325-332.

Thomas, D. R. (2006). A general inductive approach for analyzing qualitative evaluation data. American Journal of Evaluation, 27(2), 237-246.

Thorne, S. (2000). Data analysis in qualitative research. Evidence Based Nursing, 3, 68-70.

Tong, A., Sainsbury, P., \& Craig, J. (2007). Consolidated criteria for reporting qualitative research (COREQ): A 32-item checklist for interviews and focus groups. International Journal for Quality in Health Care, 19(6), 349-357.

U.S. Department of Health and Human Services. (2011). Healthy people 2020. Retrieved from http://healthypeople.gov/2020/Consortium/ HP2020Framework.pdf

U.S. Census Bureau. (2012). The foreign-born population in the United States: 2010. Retrieved from http://www.census.gov/prod/2012pubs/acs-19. pdf

Received 15 December 2013 Accepted 04 November 2014 
Copyright of Contemporary Nurse: A Journal for the Australian Nursing Profession is the property of eContent Management Pty. Ltd. and its content may not be copied or emailed to multiple sites or posted to a listserv without the copyright holder's express written permission. However, users may print, download, or email articles for individual use. 